\title{
The Teaching Reform Practice of Curriculum of Steel Quality Inspection Based on Professional Core Competence-oriented for Application-oriented Undergraduate Education
}

\author{
Bing Liu; Yan Liu; Wanjun Zhu; Yingying Li \\ Liaoning Institute of Science and Technology \\ School of Metallurgical Engineering \\ China, Liaoning, Benxi 117000
}

\begin{abstract}
The paper introduces basic ideas and methods of teaching reform of the applied undergraduate colleges' theoretical course, The Rolled Steel Quality Inspection, taking advantage of the organic combination of theoretical teaching and practical teaching and effective ways to improve students' initiative to study, such as extracurricular activities, opening laboratory and so on. At the same time, their practical ability and the ability of social service can also be exercised. The practice of course reform scheme manifests that students can comb professional knowledge systematically, and that they possess stronger abilities of operating equipment and examining products, which can enhance their employment confidence and employability so that they are more able to adapt to the employment environment.
\end{abstract}

Keywords-The rolled steel quality inspection; Teaching reform; Practical teaching

\section{INTRODUCTION}

The Rolled Steel Quality Inspection is one of the specialized courses of material type students who major in Material Shaping and Control Engineering, Metal Material Science and so on. The course introduces how to acquire constituents, structure and performance of rolled steel by using modern testing methods. By learning this course, on the one hand, students can learn the rolled steel examine-and- receive knowledge, basic knowledge and standard specification of the rolled steel quality inspection. On the other hand, they can grasp the contents and demands of quality inspection, initially possessing the examining ability of inspectors and technicians in the production field [1]

Material Shaping and Control Engineering major aim at cultivating high-quality applied talents according with the demands of local economic development. Students will be equipped with five core abilities. The first one is the production ability of operating production equipment correctly and processing metal material products. The second one is the control ability of metal materials' shaping process design, the structure property and productive process. The third one is analyzing and solving project practical problems of the metal material shaping field, which is the organization and management practical ability of the metal material shaping productive process. The forth one is favor scientific research quality. The last one is the ability of studying and exploiting new materials and new process. The aim of teaching demands us to place the students on the dominant position in the course of teaching and pay attention to improving their practical ability of the theoretical knowledge and the ability of social service. Through the teaching methods reform on the combination of theoretical teaching and practical teaching, we can further carry out the teaching activities, such as extracurricular innovation training and opening laboratory. Then, for one thing, it can exactly make the knowledge of rolled steel quality inspection concrete, visual and lively. For another, it can also fully support the core ability of metal materials' structure property inspection and analyzing and solving project practical problems of the metal material shaping field. Therefore, I will conduct a preliminary teaching reform and practice on the Rolled Steel Quality Inspection course according to the teaching condition of our school.

\section{THE PROBLEMS OF TRADITIONAL THEORY TEACHING AND}

\section{REFORM IDEAS}

The knowledge modules of the Rolled Steel Quality Inspection course constitute of chemical component examination module, Steel's micrographic examination module, and metallographic phase examination module, mechanical property examination module, processing property examination module, physical property examination module, chemical property examination module and nondestructive test module. The capability module supported by the knowledge module mainly makes up of the ability of getting and handling information, the ability of experimenting and processing data, 
analytical ability of metal materials' structure property, control ability of the quality of products, the ability of analyzing and solving the productive practical problems. The supporting relationship is as shown in the Figure 1. If you want to obtain the above-mentioned abilities, merely relying on the quondam 32 studying hours' theoretical course is far from enough. On the contrary, teachers need to instruct students to practice and exercise abundantly based on their demonstrated and checked operation. At present, in the process of teaching, the teachers mainly adopt PPT and writing on the blackboard to teach the experimental contents of the rolled steel quality inspection, inspection equipment operation and test methods, while the students can only learn examination methods by means of books and videos, which merely rest on the surface [2]. Under the circumstance, the students' rational ability of thinking cannot be transformed into practical ability and the ability of serving enterprises. Therefore, I put forward breaking the traditional theory teaching mode, centering on improving the students' practical ability, teaching theoretical courses in the laboratory under the existing experiment condition, combining the rational practical teaching and theory teaching to make up a complementation. Then the course can be guided to employment, approaching to the employment demands, which can improve the students' practical ability.
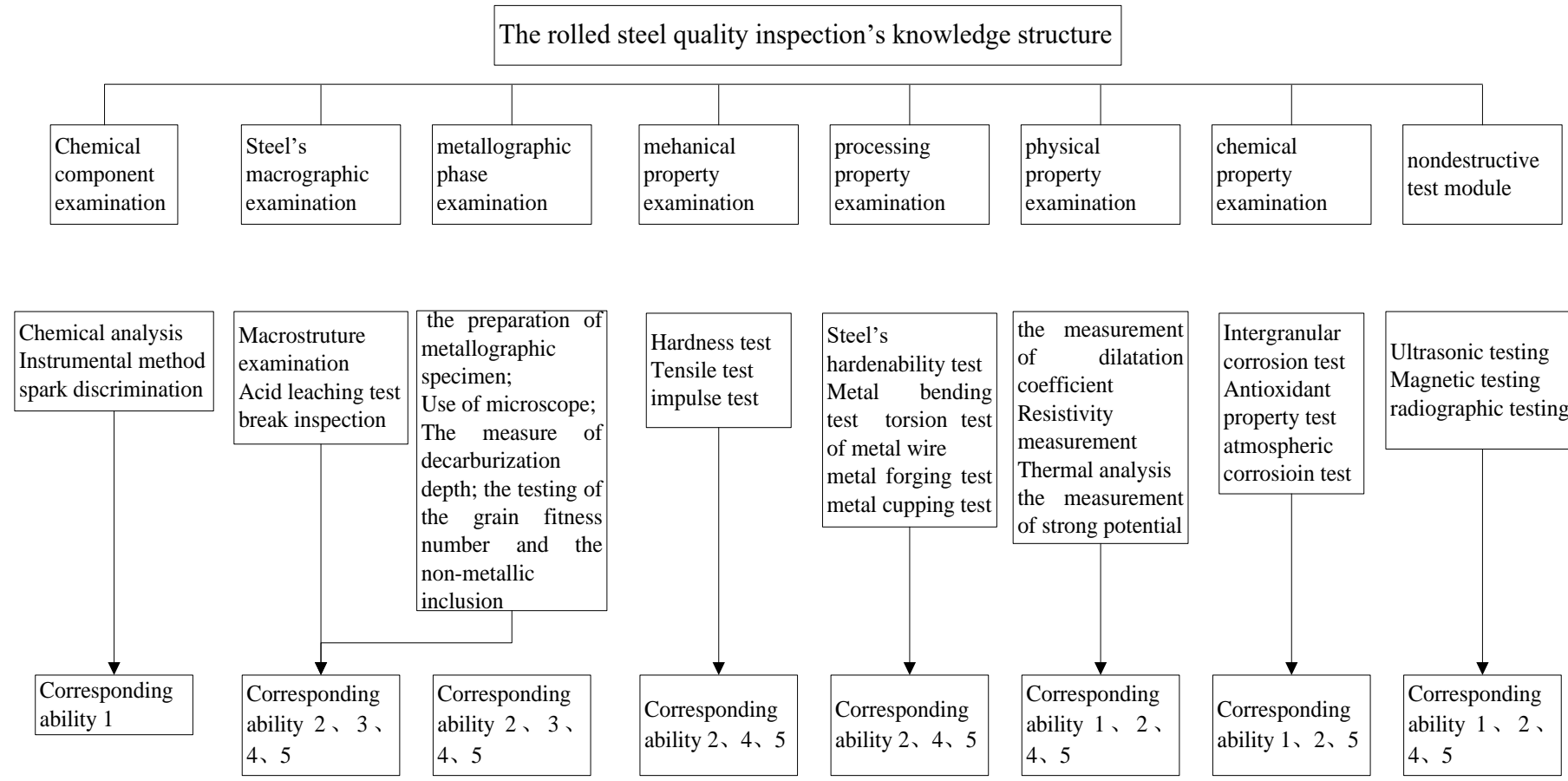

Magnetic testing

radiographic testing

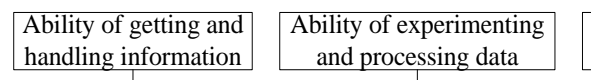
\begin{tabular}{|c|}
\hline Analytical ability of metal \\
material's structure property
\end{tabular}

Control ability of the

Ability of analyzing and solving

ther getting and \begin{tabular}{c} 
and processing data \\
\hline
\end{tabular}

The rolled steel quality inspection's ability structure

Fig. 1.Mutual support of knowledge structure and ability structure of steel quality inspection

\section{TEACHING REFORM IDEAS AND MEASURES}

\section{A. Combine the theoretical teaching and practical teaching}

\section{Improve students' learning interests.}

The rolled steel inspection technique has been developed increasingly with the progress of science and technology, which demands the students to learn new technical norms continuously, to grasp advanced examination methods and the methods of operating equipment. If the students work on the fields of the rolled steel quality inspection they need to use some conventional equipment frequently, such as metallurgical microscope, universal testing machine, micro hardness tester, scanning electron microscope and so on, depending on the
Material and Metallurgical Engineering Experiment Center of Liaoning Province. Besides, important theoretical knowledge contents in the classroom should be reached synchronously in the laboratory (including steel's chemical component examination, steel's micrographic examination, metallographic phase examination, mechanical property examination, processing property examination, physical property examination, chemical property examination and nondestructive test, 20 studying hours in total, which take up 62.5 percent of the whole studying hours) [3]. For instance, the chapter of metallographic phase examination mainly covers the operating principle of metallurgical microscope, the preparation of metallographic specimen, the metallographic phase micro examination, the testing and ranking of the grain 
fitness number and the steel's non-metallic inclusion. When teaching this section, the teacher could instruct the students to prepare metallographic phase micro specimens in the sample-preparation lab, which includes operating points of rough grinding and fine grinding and the announcements of burnishing and corroding in the specimen preparation. As shown in the Figure 2, the students are learning methods simultaneously practicing and exercising. They can both grasp the principle and learn the methods of preparation. When the preparation is over, the teacher takes advantage of the micro platform of the metallographic phase to teach the operating principle and methods of metallurgical microscope, while the students use it under different enlargement factors to observe and analyze the prepared rolled steel specimen microstructure. After the students have a knowledge of operating standards, the teacher teaches the rating standards of the grain fitness number by means of PPT, instructing the students to rank the specimens according to the operating standards. The students can still polish the same specimen and carry out the testing and ranking of the non-metallic inclusion. The teacher is teaching on one side, while the students are practicing on the other side, operating by themselves. Then they can not only have a knowledge of the methods and principle of the rolled steel inspection, but also learn the preparation of the rolled steel specimens and the operation of the examining equipment metallurgical microscope. In the course of practice, the students deepen the apprehension of theoretical knowledge, making study serve the practical purpose. And their practical ability can also be improved, which can lay a solid theoretical and practical foundation for working on the rolled steel quality inspection.

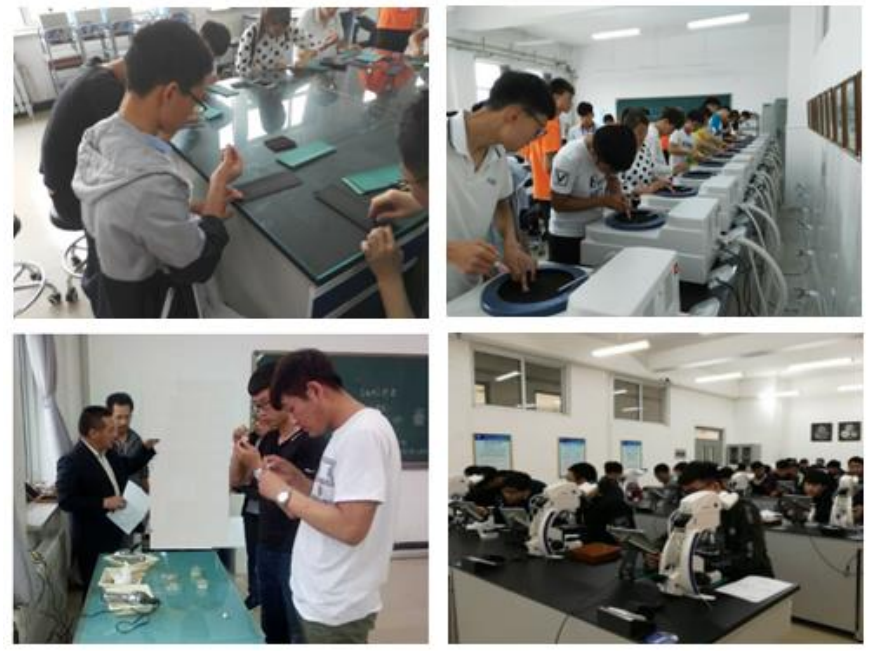

Fig. 2. Grinding, polishing, corrosion and observation of metallographic samples

\section{B. Strengthen the practical teaching Exercise the students'}

\section{practical ability}

Relying on the extracurricular innovation training and opening laboratory, the teachers organize students to hold the second-classroom activities in the spare time. The teachers can set inspection items on the basis of learning contents, scientific research project and the practical problems of enterprise production, instructing students to operate independently [4-5]. In the meantime, they should pay attention to cultivating the practical ability of students in order to keep pace of the actual jobs. However, in class, the time is limited and the pace is fast. It's often the case that the teachers' presentation is dominant. As a result, the students both absorb theoretical knowledge and learn the operating methods, so it's difficult to grasp the inspection methods entirely through a single course. On the contrary, the second-classroom activities are not bound by time in class, so the students can practice repeatedly and improve their practical ability gradually [6]. For example, in the tensile test of the mechanical property examination, the teachers conduct the mechanical property examination on the experimental material of advanced high strength steel depending on the Youth Fund Project. Simultaneously, they guide the students to take advantage of the some operating equipment like band sawing machine and wire cutting for processing and examining standard specimens according to the national standards and industry standards. In addition, they also instruct the students to conduct the tensile test using the universal tensile testing machine .Then students draw stress-strain curves and measure the ductility and reduction on area of specimens snapped. Finally, students can really learn the whole process from the preparation of testing to completion of testing to compiling inspection report. What's more, the inspection process is close to the working process of quality control personnel in the production field, which can deepen students' understanding of teaching contents of steel's mechanical property examination in practice.

\section{CONCLUSION}

With the progress of science and technology, the rolled steel is applied into all fields far and wide, so the talents of the rolled steel quality inspection are getting indispensable. Faced with drastic competition environment, I step on the employment situation and propose a teaching reform on the course of The Rolled Steel Quality Inspection according to the objective of talent cultivation. Here, I attach great importance on practical teaching and emphasize that we should train students' practical ability so as to foster applied talents with strong ability of practice and employability for the enterprise .Observing the practice of course teaching reform and the learning effectiveness of students, we could draw a conclusion that it' $s$ necessary to reform on the course. On the one hand, the teaching quality can be guaranteed and the teaching effectiveness can be improved. On the other hand, the students' practical ability can also be strengthened, which benefits them to develop into applied talents.

\section{ACKNOWLEDGMENT}

Zhu Wanjun,Qu Tao,Liu Bing,Cao Yi,Dai Lizhong,Ma Haitao,Tang Wei,Li Yingying,Wang Lin,Jiang Yunan,Wang Luning. The supporting project is the educational and teaching reform project for transitional development of Liaoning institute of science and technology. The name of the project is the practice of Material Shaping and Control Engineering major personnel training mode based on the cultivating of engineering practical ability. 


\section{REFERENCES}

[1] Liu Tianyou. Steel quality inspection [M]. Beijing: Metallurgical Industry Press.2014.

[2] Danhong Ma. Problems in Class Teaching in Chinese Universities and Countermeasures in Teaching Reform[J]. CSCanada, 2015,pp.113-117.

[3] Xue Jiao Zhou, Wen Tang Xia, Yong Li Chen, Jian Guo Yin, Hui Wang,Wen Qiang Yang. Research and Practice in the Teaching Reform of the Nonferrous Metallurgy[J]. Applied Mechanics and Materials,2012,pp.1527-1530.
[4] Jun Wang,Zijun Song,Quanliang Li.Reform of an Experimental Course of Chemical Engineering Based on Project-Based Teaching Method[J] Open Access Library Journal,2016,pp1-4.

[5] Jun Liu. Exploration on Teaching Reform and Innovation of Materia Mechanics[J].Advanced Materials Research, 2012,pp.2208-2211.

[6] Feng Dianchen, Hu Xiaoyan, Zhang Wei, Zhang Feng, et al. Teaching reform and practice of experimental teaching of metal heat treatment technology [J]. China Electric Power Education, 2014( 02) 